\title{
1 The impacts of predators and parasites on wild bumblebee
}

2 colonies.

3

4 Dave Goulson $^{1 *}$ Steph O’Connor ${ }^{2}$, Kirsty J. Park ${ }^{2}$

5

6

$7 \quad{ }^{1}$ School of Life Sciences, University of Sussex, BN1 9QG, UK

$8 \quad{ }^{2}$ Biological and Environmental Sciences, School of Natural Sciences, University of Stirling,

9 FK9 4LA, UK

10

11

12

13

14

*Author for correspondence.

15

Emails:

D.Goulson, d.goulson@sussex.ac.uk

S. O’Connor, steph.oconnor@yahoo.co.uk

This is the peer reviewed version of the following article: GOULSON, D. , O'CONNOR, S. and PARK, K. J. (2018), The impacts of predators and parasites on wild bumblebee colonies. Ecological Entomology, 43: 168-181, which has been published in final form at https://doi.org/10.1111/een.12482 This article may be used for non-commercial purposes in accordance With Wiley Terms and Conditions for self-archiving.

Running header: Monitoring survival of bumblebee colonies 
33 Keywords: Bombus; nest; predation; survival; reproduction; Aphomia sociella, Apodemus 34 sylvaticus 


\section{Abstract}

1. The study of wild bumblebee nests has been hindered by the difficulty in locating and observing them. Here, 47 wild nests were located using a sniffer dog and volunteers. The entrances to 32 nests were filmed continuously to identify successful nests (those which produced gynes) and observe vertebrate species interactions.

2. Of the 47 nests, $71 \%$ and $21 \%$ produced gynes in 2010 and 2011 , respectively.

3. A total of 39 vertebrate species were filmed at entrances but the majority did not interact with the nests. Great tits (Parus major) depredated or attempted to depredate bees on 32 occasions at the entrances to ten nests, something which has not previously been described. Small mammals were very often recorded accessing entrances to bumblebee nests, but whether they depredated bees was not known, and frequentlyvisited nests were no less likely to produce gynes. Eight nests were entered by adult wax moths, Aphomia sociella.

4. The faeces of 1,179 workers from 29 Bombus terrestris nests were screened microscopically for parasites. Crithidia bombi infections were apparent in $49 \%$ of worker bees, while Nosema bombi and Apicystis bombi were present in 5.5\% and $0.68 \%$ of bees, respectively. Nests with a high prevalence of $C$. bombi infection were less likely to produce gynes, the first evidence for a direct impact of this common parasite on bumblebee colony reproduction in wild nests.

5. Overall, our data indicate that bumblebee nests are at the heart of a rich web of interactions between many different predator and parasite species. 
Bumblebees are amongst the most abundant and important of pollinator species throughout the temperate northern hemisphere, and some have undergone marked declines in abundance and contractions of range in recent decades (Goulson et al. 2015). These declines have stimulated much research, but the study of wild bumblebee nests has been somewhat neglected as locating nests remains challenging (Kells and Goulson, 2003; Osborne et al., 2008; Suzuki et al., 2009; Lye et al., 2009). Hence we still have a poor understanding of bumblebee nesting and population biology (Osborne et al, 2008; Goulson et al., 2010; Lye et al., 2012). This is significant as the nest is, arguably, the breeding unit; each nest normally contains one breeding female, the queen (but see O'Connor et al. 2013).

Aspects of bumblebee ecology and behaviour have been studied using nests reared from wild caught queens in the laboratory or obtained from commercial bumblebee rearing companies, which are then placed in the field (e.g. Schmid-Hempel and Schmid-Hempel, 1998; Goulson and Stout, 2001; Goulson et al., 2002; Carvell et al., 2008; Whitehorn et al., 2012). The outcomes of these experiments, whilst valuable, may not always provide an accurate representation of wild bumblebees. Artificially reared bumblebee nests placed in the field tend to be housed in constructed domiciles raised above the ground and with entrances that are apparent (Lopez-Vaamonde et al., 2004; Carvell et al., 2008). They may thus be more vulnerable to attack by predators and parasites than natural nests.

Bumblebees are thought to have a number of mammalian enemies in the UK; for example, small mammals such as wood mice (Apodemus sylvaticus) and shrews (Sorex spp.) are said to enter and depredate nests before the first brood of workers have emerged (Darwin, 1859; Sladen, 1912; Cumber, 1953; Pouvreau, 1973), or they may be excavated and eaten by larger mammals such as badgers (Meles meles) (Sladen, 1912; Pouvreau, 1973; Alford, 1975) and foxes (Vulpes vulpes) (Benton, 2006; Goulson, 2010). Bumblebee nests can also fall victim to the larvae of the wax moth Aphomia sociella which consume the entire nest; destroying comb and brood (Sladen, 1912; Pouvreau, 1973; Alford, 1975; Goulson, 2010). A large proportion of our understanding of bumblebee nest predators originates from the extensive work of Sladen (1912). Whilst his book formed the foundation for later bumblebee research and many of the facts he presents are repeated in later texts, the reliability of some of his observations are questionable. For example Sladen (1912) writes that 'moles [Talpa europea] and weasels [Mustela nivalis] also destroy nests' yet later states that he has found 'no evidence for predation by any vertebrates other than mice and shrews'. Similarly in a 
90 Cumber (1953) documented that 17 were 'destroyed by rodents, badgers, etc' and 25 'died out prematurely', but no details on how this was determined is given. It is therefore unclear how rodent predation was deduced as the cause of death, or what proportions of failed nests were due to the different predators. Darwin (1859) quoted Col. Newman's estimate that 'Two thirds of bumblebee nests are destroyed by field mice' but again, methods for assigning mice as the cause of failure are not given. Casual observation of bumblebee nests is unlikely to produce useful data in this respect since vertebrate predators are likely to modify their behaviour if a human observer is present, and most are nocturnal. Further clarification of the predators of bumblebee nests and quantification of the rates of their destruction is needed to advance understanding of bumblebee nest ecology and facilitate development of suitable conservation strategies (Goulson, 2010; Winfree, 2010).

As with rates of predation, we also have poor data on the frequency with which bumblebee nests survive to produce gynes or males. Data on wild nests in the UK is limited to the study by Cumber (1953) who found $23(28.8 \%)$ of 80 B. pascuorum nests produced gynes. Experiments using artificially reared nests find varying levels of reproduction. For example, 25 commercially reared $B$. terrestris colonies placed in the field resulted in a mean of 13.7 gynes per nests ( \pm 5.7 ) with $11 / 25(44 \%)$ of nests failing to produce gynes (Whitehorn et al., 2012). Of 36 laboratory reared B. lucorum nests, 5 (13.9\% of nests) produced gynes, ranging from 1 to 125 per nest and totalling 250 (Müller and SchmidHempel, 1992), and in another study of 32 B. lucorum nests, $21.9 \%$ produced gynes (Imhoof and Schmid-Hempel, 1999). Others reported lower success; for example none of 14 laboratory reared B. terrestris colonies placed in the field produced gynes (Otti and Schmid-

112 Hempel, 2008). It has been hypothesised that the majority of nest failures occur in the very

113 early stages when the founding queen is solely responsible for establishing a nest (Sladen,

114 1912; Free and Butler, 1959; Alford, 1975), so figures obtained from laboratory reared nests 115 or those followed in the wild after the first brood have hatched are likely to be overestimates. 116 Infection by internal parasites may also affect the survival and reproductive success of 117 bumblebee colonies (Durrer and Schmid-Hempel, 1995; Brown et al., 2003; Otti and Schmid-

118 Hempel, 2007), but the impact these parasites have on wild bumblebee nests has never been 119 quantified.

120 Here, we deploy cameras to film wild bumblebee nest activity, detect gyne 121 production, and to record visits by vertebrate predators, A. sociella or cuckoo bees

122 (Psithyrus). We also screen workers for internal parasites, providing a detailed account of the 123 factors affecting the fates of 47 bumblebee nests. 


\section{Methods}

126 The work took place on the University of Stirling campus and nearby farmland in 2010 and

127 2011. A trained bumblebee nest detection dog and volunteers assisted in locating nests

128 (Waters et al. 2011; O’Connor et al., 2012). Searches were focussed on areas likely to have

129 bumblebee nests, particularly woodland and semi-natural grassland (Cumber, 1953; Alford,

130 1975; Svensson et al., 2000; Free and Butler 1959; Fussell and Corbet, 1992). Woodlands

131 comprised a mix of mature stands of oak (Quercus robur), ash (Fraxinus excelsior) and

132 beech (Fagus sylvatica) with some areas of younger deciduous trees and small areas of

133 planted coniferous woodland. Grasslands were semi-natural, ungrazed and characterised by

134 presence of tussocks of dead grasses and herbs. All sites had to be suitable for repeat visits

135 and for use of recording equipment, therefore areas of dense undergrowth, those prone to

136 water logging or next to roads and paths were not searched to avoid risk of equipment theft or

137 vandalism. On occasions, nests were found which were deemed too close to paths, and some

138 were reported by farmers in outbuildings. These were observed for a minimum of $20 \mathrm{~min}$

139 twice each week and parasite samples were taken but they were not filmed.

\section{Cameras}

142 Ten camera recorders were designed and manufactured by N. Butcher at the Royal Society

143 for the Protection of Birds Headquarters, Sandy, UK. Each consisted of a black and white,

144 waterproof camera, (Misumi, MO-R430G-C) with a resolution of 240 T.V. lines. Six

145 infrared, no-glow bulbs were positioned around each of the ten cameras to facilitate night

146 filming. Infrared lighting was controlled by a digital timer, housed inside the weather proof

147 box. A metal hood fitted over and around the camera (and infrared bulbs) and measured

148 approximately $6 \times 4 \times 3 \mathrm{~cm}$. This was connected to a metal stake $50 \mathrm{~cm}$ in length. Both hood

149 and stake were painted with a green and brown pattern to camouflage the camera. The metal

150 stake was driven into the ground to hold the camera in position approximately $40-60 \mathrm{~cm}$ from

151 the bumblebee nest entrance. The camera was connected via a $4 \mathrm{~m}$ cable to a 12 Volt battery

152 and a MemoCam Digital Video Recording unit, (Video Domain Technologies Ltd., Petah

153 Tikva, Israel), which was housed inside a plastic weatherproof box (approximately $15 \mathrm{x} 15 \mathrm{x}$

$15412 \mathrm{~cm}$ ). The weather proof box and battery were wrapped in a waterproof sack and buried

155 inside a shallow pit, $4 \mathrm{~m}$ from the camera. The turf from the excavation was replaced above

156 the equipment to minimise disturbance and provide camouflage. The wire was also buried

157 just below the surface of the ground. 
159 The MemoCam software package was designed for surveillance operations and has been used

160 for vertebrate observational studies (Bolton et al., 2007). The software allows the user to

161 specify an area of the filmed image to be movement sensitive. In this case the nest entrance

162 was selected. The software detected any movement at the nest entrance and recorded one

163 frame before this movement and the following five frames. This ensured there was no time

164 lag between the movement trigger and start of filming, as was found to be an issue with other

165 commercially available wildlife camera traps. Sensitivity was set so that movement of

166 anything greater than $\sim 3 \mathrm{~mm}$ in diameter would trigger recording (i.e. the very smallest

167 bumblebees were filmed, but diminutive flies were unlikely to trigger recording). Footage

168 was recorded onto 2 G.B. 'mini' S.D. memory cards. Batteries and memory cards were

169 replaced every two to three days. When a nest expired, the camera was redeployed to a

170 newly-discovered nest as quickly as possible.

\section{Video analysis}

173 Footage was viewed at $\mathrm{x} 2$ real time. Any events which were of interest were watched again at 174 slower speed to establish their exact nature. The number of bees entering and leaving nests 175 was recorded for one hour, from 12:00-13:00 hrs, each day and termed 'midday traffic'. In

176 some cases the nest was visited at midday by researchers, (changing batteries, S.D. cards, 177 etc, ) and in these cases, bumblebee traffic for the hour nearest to midday was used. For every

178 day that a nest was filmed, a seven-day running mean of the midday traffic was calculated

179 (the mean of the traffic on the day in question, plus the traffic on the previous and following

180 three days). The greatest value of seven-day mean midday-hour traffic was termed 'peak

181 traffic' and used as a proxy measure for the maximum size attained by each nest for statistical 182 analysis.

183 All vertebrates filmed within approximately $1 \mathrm{~m}$ of the entrance were identified to

184 species and their behaviour was recorded. Behaviours were categorised as: no interaction

185 (where animals simply passed nest entrances); some interaction (sniffing at entrance, waiting

186 at hole); attempted predation (widening entrance, chasing bumblebee foragers) and predation

187 (bees killed); or entering or exiting the nest entrance. For each species, rates were calculated

188 for attempted predation/predation or use of nest entrance by dividing the total number of

189 events by the total number of days that the nest was filmed. Small mammals are more active

190 at night, with very few records during daylight hours. Their numbers were calculated for each

$19124 \mathrm{hr}$ period beginning at $8 \mathrm{am}$ (instead of for example, midnight which would result in 
192 nightly visits being split over two days). For small mammals which entered the hole, we 193 would expect a visit to consist of one record of entry followed by one record of exit, but this

194 was not always the case (presumably because some holes led to underground tunnel networks 195 with multiple exits). In this case, the number of entries or exits per $24 \mathrm{~h}$ period (whichever

196 was the greater) was used.

197

\section{Screening for internal parasites}

199 Faeces from B. terrestris workers from 29 nests were screened for the internal parasites Nosema bombi, Crithidia bombi and Apicystis bombi. Faecal samples were collected from

201 five bees twice weekly from each nest where possible. Bumblebees were collected at their nest in clean sample pots. They were released when they defecated or after 15 min. Faeces were collected from the pot using a microcapillary tube which was then sealed at both ends with PTFE tape, labelled and chilled on an ice block in the field before being refrigerated at $2-5^{\circ} \mathrm{C}$. Each bee was examined for signs of wing wear and assigned to one of four categories (after Carter,1992; Rodd et al., 1980; Müeller and Wolfmueller, 1993; Whitehorn et al., 2011): $0=$ no wing wear; 1 , some minor indentations; 2 , most of margin with minor indentations; 3 , more than 5\% wing surface missing. In the laboratory, samples were transferred to a haemocytometer within 24 hours and examined under a light microscope at x400 magnification. The presence of $N$. bombi, C. bombi and A. bombi was recorded and

211 numbers of each within $0.1 \mu \mathrm{L}$ on the haemocytometer grid was counted. Counts of $C$. bombi

212 and N. bombi correlate with intensity of infection (Otterstatter and Thompson 2006; Otti and

213 Schmid-Hempel 2008). Bees were not marked after sampling, so it is possible that some

214 individual bees were screened more than once. Bees were caught as they entered or left the

215 nest; it is possible that these bees were intruders from another nest, but this is likely to be

216 very infrequent (O’Conner et al. 2013).

\section{$218 \quad$ Nest success}

219 We use gyne production as the measure of nest success, since the numbers of colonies in the next generation depends upon the numbers of gynes (Chapman and Bourke 2001). In addition to observation of video footage, gyne production can be detected by the presence of queen cells in the nest and so once nest activity ceased we attempted to excavate them. However, it was rarely possible to get to the nests (usually prevented by large tree roots), so these data are not included. 
The most common bumblebee species studied here was Bombus terrestris, in which males and workers cannot be distinguished from camera footage, so detection of male production was unreliable. Males could only be reliably distinguished for B. pratorum and $B$. lapidarius of the species studied here.

\section{Statistical analysis}

231 Statistical analysis was carried out using R Statistical Software Version 2.12.2 (R

232 Development Core Team, 2011). Model fit was checked by visual examination of residuals.

233 Over-dispersion in the data was assessed and any points with Cook's Distance of greater than

2341 were removed from analysis due to disproportionate influence on the data set (Zuur et al., 235 2007).

A $\chi^{2}$ test was used to compare the proportion of nests producing gynes in 2010 versus 2011 , for all bumblebee species combined. This analysis included both filmed nests and those that were observed bi-weekly. A General Linear Model (GLM) with binomial distributions was used to assess the effect of 'peak traffic' and 'days filmed' (a proxy for nest duration) on the likelihood of each nest producing gynes, using data from the filmed nests only. Data from all bumblebee species were pooled as there were too few nests of species other than $B$. terrestris for meaningful analysis (Table 1). However, the analysis was rerun excluding $B$. pratorum (a species in which nests end early) in case this influenced the results.

Four separate GLMs were used to investigate the likelihood of A. sylvaticus, Sorex spp., great tits (Parus major) and A. sociella visiting bumblebee nests. The response variable used for each of these models was the total number of visits from the species of interest to each nest, using 'year' as a fixed factors and 'peak traffic' as a covariate in the model. As above, data from all bumblebee species were pooled. Models used quasi-Poisson distributions to account for over-dispersion in the data. Some data points were removed from the analysis (two nests each A. sylvaticus, Sorex spp. and P. major and one nest from the A. sociella model) because these data were outliers (Zuur et al., 2007). There were too few nests visited by bank voles (Clethrionomys glareolus) or field voles (Microtus arvalis) to allow statistical analysis (four and three nests, respectively).

A GLM with a binomial distribution was used to assess the effect of visits from $A$. sylvaticus, Sorex spp., P. major and A. sociella upon gyne production (binary response), including 'peak traffic' as a covariate. factors that influenced the likelihood of a $B$. terrestris worker bee carrying either a $C$. bombi 
or a $N$. bombi infection. The model used 'presence of infection' (of either C. bombi or $N$. bombi) as the binary response, with the following potential explanatory variables: 'year', 'habitat', and 'presence of other protozoan infection' (i.e. either C. bombi or N. bombi, whichever was not being used as response) as fixed factors in these two models. 'nest' (i.e. the nest from which the worker was caught) was used as a random factor, and 'day' (i.e. day on which the sample was taken; day one being the first day a nest was found in that year) as a covariate. The interaction between 'year' and 'day' was also included.

To assess the impact of infections with either C. bombi or $N$. bombi on nest success, i.e. gyne production, a GLM with binomial distributions was used to assess the likelihood of B. terrestris nests producing gynes (the binary response), with the 'proportion of infected bees' for C. bombi, N. bombi as covariates and presence or absence of $A$. bombi as a fixed factor.

\section{Results}

A total of 47 bumblebee nests were found between 10 June and 25 August, and followed until their demise. In 2010, 28 nests were located and 19 of these were filmed. In 2011, 19 nests were found and 13 were filmed (Table 1). The majority were B. terrestris (34), with small numbers of other species; Bombus hortorum (4), Bombus lapidarius (3), Bombus lucorum (2), Bombus pascuorum (2) and Bombus pratorum (2).

\section{Gyne production}

Across all 47 nests (i.e. all species and both filmed and observed nests) gyne production was significantly greater in 2010 than 2011 with gynes successfully produced by $71.4 \%$ and $21.1 \%$ of nests in 2010 and 2011 , respectively $\left(\chi^{2}{ }_{1}=12.7, P<0.001\right.$; Figure 1a). The pattern remains similar if we use only the more reliable data for filmed nests $(63 \%$ versus $23 \%$ of nests produced gynes in 2010 and 2011, respectively). Two nests (nests 27 and 29; Table 1) failed on or soon after the day that they were found (i.e. $>2$ bees were seen to enter or leave the entrance, but thereafter, either no or very few $(<5)$ bees were seen. It is highly unlikely that gynes could have been made by these nests, but as we have no estimations of peak traffic, vertebrate species visits, etc, these two nests were not included in statistical analysis of predator/moth visits etc.

Of the filmed nests suitable for analysis, $(n=30)$ those with high "peak bumblebee traffic' were significantly more likely to produce gynes $\left(\mathrm{F}_{1,28}=40.3, P<0.001\right.$; Figure $\left.1 \mathrm{~b}\right)$. The likelihood of nests producing gynes was not related to the duration of nest filming $\left(\mathrm{F}_{1,28}\right.$ 

$=0.80, P=0.379$; Figure 1c) and this was not affected by removing data for $B$. pratorum.

294 Therefore data were collected approximately equally for both nests that successfully produced gynes and nests that failed to produce gynes.

\section{Species interactions with bumblebee nests}

298 Thirty-three vertebrate species were recorded at bumblebee nest entrances on at least one occasion (Table 2) in addition to the wax moth A. sociella, cuckoo bumblebees (Psithyrus) and other true bumblebees. The majority of large vertebrates filmed did not interact with the bumblebees or their nests.

a) Mammals

The most commonly observed interactive vertebrates were rabbits (Oryctolagus cuniculus) and grey squirrel (Sciurus carolinensis), both of which are very common in the study area. Sometimes they dug in leaf litter near the nest entrance, but they did not appear intent on gaining access to nests, did not attempt to interact with bees, and were regularly observed carrying out similar behaviour away from nest entrances. Erinaceus europaeus were filmed investigating entrance holes and enlarging the entrance in what appeared to be deliberate access attempts on seven occasions, but they were unable to penetrate in to any of the nests (Figure 2).

Small mammals were very frequently recorded entering and leaving nest entrances, particularly A. sylvaticus. However, these events may indicate shared occupancy of the burrow system rather than predation of bumblebee nests and these observations are therefore difficult to interpret. However, at two nests, (nests 16 and 23; Table 1) wood mouse visits peaked during a single night and no bumblebee traffic was seen thereafter (Figure 3). In these instances, mice carried leaf litter into the entrances and in one case (Figure 4) excavation of the tunnel revealed that the tunnel had been tightly blocked with leaf litter and more than 50 live but subdued adults and considerable numbers of pupae and larvae remained in the nest, suggesting that the blockage had ended nest activity prematurely.

Visits from A. sylvaticus to nests were not influenced by year, $\left(\mathrm{F}_{1,28}=1.16, P=0.291\right)$ or peak bumblebee traffic $\left(\mathrm{F}_{1,28}=1.23, P=0.276\right)$. Numbers of Sorex spp. visits to bumblebee nests differed significantly between years $\left(\mathrm{F}_{1,28}=44.86, P<0.001\right.$; Figure 6$)$ but were not influenced by bumblebee traffic $\left(\mathrm{F}_{1,28}=0.020, P=0.890\right)$. There were too few nests visited by bank and field voles to allow statistical analysis. 
Neither A. sylvaticus nor Sorex spp. visits affected the likelihood of a nest producing gynes $\left(\chi^{2}{ }_{1}=0.48, P=0.485\right.$ and $\chi^{2}{ }_{1}=0.32, P=0.571$, for $A$. sylvaticus and Sorex spp., respectively).

\section{b) Birds}

A number of bird species were seen investigating nest entrances (Table 2), but only P. major were observed to depredate bees. Foragers/males and gynes were observed being captured as they departed from or returned to the nest. On a total of 32 occasions at six nests, the birds pecked at walking bees, but also appeared to watch returning bees before they landed and occasionally pursued bees into the air. Great tits were also filmed exhibiting 'stalking behaviour' on 17 occasions at eight nests (i.e. remained at entrance holes, looked inside, removed leaf litter from the entrance, etc,) but no bees were present at the time. Stalking, predation attempts or successful predations took place at ten nests, in both years, at sites up to $4 \mathrm{~km}$ apart.

The number of $P$. major depredations were not significantly different in either year $\left(\chi^{2}\right.$ $1=1.13, P=0.470)$. There appeared to be a trend for $P$. major to target larger nests with greater peak bumblebee traffic than smaller nests with infrequent bumblebee traffic, but this trend was not significant $\left(\mathrm{F}_{1,28}=7.94, P=0.057\right.$; Figure 5). Parus major attacks were positively correlated with gyne production $\left(\chi^{2}{ }_{1}=5.47, P=0.019\right.$, Figure $\left.7 \mathrm{a}\right)$.

c) Invertebrates

Aphomia sociella, were filmed entering and leaving 8 of the 30 filmed nests, but the likelihood was not affected by the year $\left(\mathrm{F}_{1,28}=0.92, P=0.443\right)$ or peak bumblebee traffic $\left(\chi^{2}\right.$ $1=1.92, P=0.279)$. Aphomia sociella visitations were positively correlated with gyne production $\left(\chi^{2}{ }_{1}=3.88, P=0.049\right.$, Figure $\left.7 b\right)$.

A Bombus sylvestris (cuckoo bumblebee) female was filmed exiting a $B$. pratorum nest $5^{\text {th }}$ June 2011 (nest 20; Table 1). Within seven days the nest traffic was much reduced to 0-4 bees per hour. No other Psithyrus were observed.

One B. lapidarius nest was visited by 14 B. terrestris or B. lucorum workers (Figure 8) over six days. None of the B. terrestris visitors were carrying pollen and so cohabitation of the burrow system seems doubtful.

A queen B. terrestris or B. lucorum entered a small B. terrestris nest on $8^{\text {th }}$ July 2010 (nest 17; Table 1) and a queen exited the nest approximately twelve minutes later. The queen walked around the entrance of the nest for some time, eventually walking out of view. 
Whether this bee was the founding queen or an intruder is unclear as the nest was queenless eight days later when it was excavated. Subsequent genetic analysis of the remaining twelve workers showed that they were sisters (O’Connor et al., 2013). Similarly, a B. terrestris or B. lucorum queen was filmed entering a B. terrestris nest (nest 10; Table 1) in early July, and subsequent genetic analysis of nest mates showed that there were unrelated individuals in the nest but the foreign queen was not found (O'Connor et al., 2013).

d) Internal parasites

In total 1,179 faecal samples from B. terrestris workers from 29 nests were examined for infections of the three protozoan infections (682 and 497 collected in 2010 and 2011, respectively). Crithidia bombi was far more prevalent (49.0\%) than N. bombi (5.54\%) and only eight bumblebees $(0.68 \%)$ were infected with $A$. bombi (bees from five nests, all detected in 2010). All 29 nests contained at least one worker infected with C. bombi, while $62 \%$ of nests had at least one bee infected with N. bombi. with increased wing wear (assumed to be older bees) compared to unworn, younger bees $\left(\chi^{2}{ }_{3}\right.$ $=60.89, P<0.001$; Figure 9 ). There was a significant 'year by day' interaction; $B$. terrestris were less likely to present $C$. bombi infections towards the end of the summer and this decline was more marked in $2011\left(\chi^{2}{ }_{1}=11.00, P<0.001\right.$; Figure 10). Infection with $N$. bombi was not (quite) significantly associated with $C$. bombi infection, though the relationship was positive $\left(\chi^{2}{ }_{1}=3.82, P=0.051\right)$. Crithidia bombi infections did not spread through all nest mates in wild B. terrestris nests (Figure 11 shows two typical examples of sampled nests). There were often uninfected and infected bees collected within the same sample, and intensity of infections varied greatly.

The likelihood of a $B$. terrestris worker presenting a $N$. bombi infection was significantly affected by 'year' $\left(\chi^{2}{ }_{1}=15.16, P<0.001\right)$ with a far greater proportion of $N$. bombi infections detected in 2010 (9.1\% and $0.90 \%$ in 2010 and 2011, respectively). Bumblebees infected with $C$. bombi were significantly more likely to be infected with $N$. bombi $\left(\chi_{1}^{2}=11.34, P<0.001\right)$. The likelihood of a $B$. terrestris worker being infected with $N$. bombi was not associated with bee wing wear $\left(\chi_{3}^{2}=0.27, P=0.965\right.$; Figure 9$)$. There was no relationship with 'day' $\left(\chi^{2}{ }_{1}=0.1, P=0.750\right)$ and there was no 'day' by 'year' interaction $\left(\chi^{2}{ }_{1}=0.23, P=0.630\right)$.

The likelihood of a $B$. terrestris nest producing new gynes was not affected by presence of $A$. bombi in at least one worker $\left(\chi^{2}{ }_{1}=0.447, P=0.580\right)$, nor by the proportion of 
workers infected with $N$. bombi $\left(\chi^{2}{ }_{1}=0.217, P=0.641\right)$. The proportion of workers infected with $C$. bombi was a significant negative predictor of the likelihood of a nest producing gynes, $\left(\chi^{2}{ }_{1}=7.433, P=0.006\right.$; Figure 12$)$.

\section{Discussion}

The proportion of nests producing gynes varied between the two years of observations with more nests producing gynes in 2010 than 2011. No obvious reason for this disparity was observed in the field and the trend was not explained by rates of other species visitations to nests. Indeed, the proportion of B. terrestris infected with C. bombi and N. bombi was appreciably lower in 2011, but this is unlikely to have caused any reduction in gyne production. Gyne production was positively predicted by peak traffic, suggesting that intensive monitoring of nest traffic can provide useful data on the strength of bumblebee nests. Bumblebee nests can utilize multiple entrance holes, sometimes metres apart (D.G. pers. obs.), which might influence both measurements of traffic and of gyne production, but if this did occur in our nests it was not sufficient to obscure the relationship between the two. Perhaps surprisingly, gyne production was not predicted by colony duration, but it should be noted that our estimate of colony duration (the length of time for which we observed it) was crude, since we do not know when colonies were founded and hence how long they had been in existence when we located them.

\section{Interactions with mammals}

Despite many indications in the literature that large mammals such as $M$. meles and perhaps V. vulpes are predators of bumblebee nests (Sladen, 1912; Pouvreau, 1973; Alford, 1975; Goulson, 2010), no such events were recorded in our study. We have never discovered sets of M. meles in the study area, so it is likely that they are locally absent. However, V. vulpes is locally abundant and was captured four times on camera traps but showed no interest in the nests. Furthermore, O'Connor (2013) surveyed studies of the diet of $V$. vulpes; of 2,617 scat samples that have been dissected for identifiable prey parts, none contained fragments of Bombus. Together, this suggests that Sladen (1912) may have been incorrect on this point. Erinaceus europeaus were observed investigating nests, and had these been surface nests such as those of B. pascuorum is seems plausible that they may have attempted to depredate them, but they were unable to access these subterranean nests of $B$. terrestris.

Visits by smaller mammals were very frequent. All bumblebee nests were found in networks of nests, runs and burrows which appeared to have been made by other animals, 
which is a well-known trait of bumblebees (Sladen, 1912; Alford, 1975; Lye et al., 2012).

Camera footage indicated that the majority of these burrows were frequented by mice, shrews and/or voles at the time of bumblebee occupation (Table 2). Early literature suggests that these small mammals are major predators of bumblebee nests (Darwin, 1859; Sladen, 1912; Cumber, 1953; Pouvreau, 1973), but we found no evidence for this. Visits by small mammals were not targeted towards large nests, and nor did they predict subsequent gyne production. Sorex spp. were more common in 2011, when fewer nests produced gynes, but we suggest that this is unlikely to be causative since the nests visited by Sorex spp. did not have a reduced likelihood of producing gynes.

So far as our data indicate, it seems most likely that small mammals are simply sharing the burrows, using them at night when the bees are inactive. However, it is important to note that Sladen (1912) suggests that small mammals may primarily depredate very young nests, when only the queen is present. Our nests were detected by the presence of worker traffic or by their smell, and all had workers present when located. Thus, we can infer nothing about predation levels early in the season.

Filming inside bumblebee nest (perhaps using an endoscope) would be needed to establish the actual relationships between small mammals and bumblebees. Such footage would also facilitate examining interactions out-with the scope of this study (e.g. effects of Talpa europaea). It would also be extremely interesting to film incipient nests as, in addition to small mammal attacks, this is when most usurpations and nest failures are thought to take place (Alford, 1975). However, finding and filming such nests in the wild poses a serious challenge.

\section{Interactions with birds}

452 Parus major were previously known to depredate vulnerable/walking bumblebees, including

453 bees feeding on Rhododendron spp. (Free and Butler, 1959) or Tilia spp. (Sladen, 1912;

454 Benton, 2006) which seem to have an intoxicating effect on bees, and also when infected 455 with Sphaerularia bombi (Bols; quoted in Benton, 2006). However, this is the first time that P. major have been found to depredate 'healthy' bumblebees and identifies them as a potentially significant predator of bumblebee nests, for almost a third of filmed nests were targeted by them, and P. major is an abundant species across much of Europe and Asia. It would be useful for further filming of nests to be carried out elsewhere to establish if this

460 behaviour is restricted to the region or is common elsewhere. Parus major tend to attack nests with high traffic which were likely to produce (or be producing) gynes, and it seems likely 
that this was simply because these nests were easier to locate. Since they were observed capturing gynes it is possible that they are having a significant impact at the population level.

Other bird species such as Corvus corone, Erithacus rubecula and Turdus merula also appeared to show interest in bumblebee nests.

\section{Interactions with invertebrates}

Eight nests were entered by A. sociella, the larvae of which can be highly damaging to bumblebee nests (Sladen 1912; Free and Butler, 1959; Pouvreau 1973; Alford 1975; Goulson et al., 2002). As with P. major, visits were targeted at nests that were likely to go on to produce gynes, perhaps because these nests were large and therefore more easily detected. However, this positive relationship suggests that the moths may not have had a major impact on nest success, perhaps because moth infestations that begin in summer are unlikely to cause significant damage before the nest has produced new gynes. Of course, it may be that these nests would have produced more gynes if not infested.

We recorded few other interactions with the larger invertebrates detectable with our cameras. Only one Psithyrus was observed, a single B. sylvestris queen was recorded exiting a $B$. pratorum nest. Nest traffic dwindled thereafter, but since the observation was made in June, nests of $B$. pratorum (which is an early species) tend to be at the end of their natural life at this time. We recorded no Psithyrus entering nests of $B$. terrestris, which is unsurprising given that its main cuckoo bee associate is Bombus vestalis, which did not occur in Scotland at the time (Benton, 2006). It should also be noted that, as with predation by small mammals, Psithyrus are thought to attack mainly when their host nests are small, so it is likely that we may have missed much of this activity.

We did record one instances of repeated entry of a $B$. lapidarius nest by $B$. terrestris/lucorum workers, and it seems likely that they were stealing nectar as this has been reported before (Free and Butler, 1959; Andrews, 1969). The B. lapidarius nest had already produced gynes, but it seems likely that if a nest were invaded at an earlier stage, the effect could be detrimental to the host colony, either through reducing food stores or horizontal pathogen transmission. Intra-specific robbery may also occur, but we could not detect this with our cameras.

It appeared that a failed usurpation attempt was recorded at one B. terrestris nest and potentially a successful usurpation at another. Usurpation by true bumblebee queens is thought to occur early in the season, (Sladen, 1912; Alford, 1975; Donovan and Weir, 1978; Paxton et al., 2001) whereas the potentially successful usurpation occurred later in the season. 
496 These were the only detected incidences of nest usurpation which is surprising considering

497 the frequency found in previous studies. For example, of 48 artificially reared $B$. terrestris

498 nests which were placed in the field in spring time, 18 colonies were invaded by a total of 30

499 wild B. terrestris queens (Carvell et al., 2008). However, these were not wild nests but were

500 lab-reared and placed in artificial boxes, which may be more easily detected.

\section{Effects of internal parasites}

503 Infections of $C$. bombi and $N$. bombi spread horizontally between nest mates consuming contaminated nectar and pollen from stores in wax pots within nests, via contact between individuals or shared contact with larvae, (Otti and Schmid-Hempel 2008; Erler et al., 2012; Folly et al. 2017) or between foragers visiting flowers which have recently been contaminated by an infected bumblebee (Durrer and Schmid-Hempel, 1994; Rutrecht et al., 2007; Graystock et al. 2015). In broad accordance with earlier studies, C. bombi was found to be the most common of the three parasites, followed by $N$. bombi at low prevalence and with A. bombi being very scarce. Rates of infections of C. bombi and N. bombi have been found to vary greatly between bumblebee species, populations and years (Otti and Schmid-Hempel, 2008; Popp et al., 2012), and we found that N. bombi prevalence was tenfold higher in 2010 (the year when gyne production was higher) compared to 2011.

Neither N. bombi nor A. bombi infections were associated with any measurable negative impact on traffic or gyne production (though this does not of course demonstrate that they are not harmful to their hosts). Interestingly, $N$. bombi infections were more frequent in individuals that were also infected with $C$. bombi, which may be because the presence of one parasite impairs the immune response, enabling attack by a second, or alternatively may be because jointly infected bees possess behavioural traits that render them more likely to be exposed to both parasites. For example, their preferred flower(s) may be ones on which rates of pathogen contamination are high.

In accordance with previous studies we found that older bumblebees were more likely to be infected with $C$. bombi and this is thought to be due to increased exposure and reduced immune response (Shykoff and Schmid-Hempel, 1991; Otterstatter and Thompson, 2006). However, in contrast to previous studies we also found that, having taken into account the effects of bee age, prevalence dropped in late season, particularly in 2011 . We are unable to explain this pattern.

To our knowledge, ours are the first data on patterns of changing parasite prevalence in truly wild bumblebee nests, and also the first to provide evidence that these parasites might 
530 impact on the success of wild nests. We found that nests with a high prevalence of infection

531 of workers with C. bombi were less likely to produce gynes. Without experimental manipulation (for example by inoculating some nests in early season) we cannot be sure that

533 this relationship is causative, however, and C. bombi is generally thought to have relatively

534 mild effects on its host (Brown et al., 2000) (though when combined with other stress is can strongly impact on queen founding success, Brown et al. 2003).

Overall, our data provide a unique insight into the relationships between bumblebees and their predators and parasites, identifying many new questions and avenues for further research. It would be fascinating to continue this further; for example, we gathered insufficient data on any species other than $B$. terrestris to be able to detect differences between bee species in their susceptibility to predators, but such differences are likely. The discovery of regular predation by $P$. major at the entrances to bumblebee nests suggests the possibility of significant negative impacts at the population level that were hitherto unsuspected. Interactions with small mammals are likely to be very frequent but require further investigation to indicate what happens beneath the ground. It is clear that bumblebee nests are at the heart of a complex web of interactions with diverse predators and parasites which we are only just beginning to describe.

\section{Acknowledgements}

We would like to thank field assistants and volunteers for their dedicated assistance. P. Whitehorn for instruction on internal parasite analysis, J. Struthers at Stirling University and other land owners for allowing the experiments to be conducted. Thanks also to N. Butcher at R.S.P.B. for manufacture of the camera recorders and the Leverhulme Trust for partly funding this research.

\section{References}

Alford, D.V. (1975) Bumblebees. Davis-Poynter Ltd., London. Andrews, C. (1969) The lives of Wasps and Bees. Chatto and Windus, London. Benton, T. (2006) Bumblebees. HarperCollins Publishers, London. nests using digital camera technology. Journal of Field Ornithology 78, 213-220. virulence in a trypanosome infecting bumblebees. Oikos 91, 421-427. 
563

564

565

566

567

568

569

570

571

572

573

574

575

576

577

578

579

580

581

582

583

584

585

586

587

588

589

590

591

592

593

594

595

Brown, M.J.F., Schmid-Hempel, R. and Schmid-Hempel, P. (2003) Strong context dependent virulence in a host-parasite system: reconciling genetic evidence with theory. Journal of Animal Ecology 72, 994-1002.

Carter, R.V. (1992) Morphological senescence and longevity: and experiment relating to wing wear and lifespan in foraging wild bumblebees. Journal of Animal Ecology 61, 225-231.

Carvell, C., Rothery, P., Pywell, R.F. and Heard, M.S. (2008) Effects of resource availability and social parasite invasion on field colonies of Bombus terrestris. Ecological Entomology 33, 321-327.

Chapman, R.E. and Bourke, A.F.G. (2001) The influence of sociality on the conservation biology of social insects. Ecology Letters 4, 650-662.

Cumber, R.A. (1953) Some aspects of the biology and ecology of the humble-bees bearing upon the yields of red clover seed in New Zealand. New Zealand Journal of Science and Technology 34, 227-240.

Darwin, C. (1859) The Origin of Species. John Murray, London.

Donovan, B.J. and Wier, S.S. (1978) Development of hives for field population increase, and studies on the life cycle of the four species of introduced bumblebees in New Zealand. New Zealand Journal of Agricultural Research 21, 733-756.

Durrer, S. and Schmid-Hempel, P. (1994) Shared use of flowers leads to horizontal pathogen transmission. Proceedings of the Royal Society of London, B 258, 299-302.

Durrer, S. and Schmid-Hempel, P. (1995) Parasites and the regional distribution of bumblebee species. Ecography 18, 114-122.

Erler, S., Popp, M., Wolf, S. and Lattorff, H.M.G. (2012) Sex, horizontal transmission, and multiple hosts prevent local adaptation of Crithidia bombi, a parasite of bumblebees (Bombus spp.) Ecology and Evolution 2, 930-940.

Folly, A.J., Koch, H., Stevenson, P.C. and Brown, M.J.F. (2017) Larvae act as a transient transmission hub for the prevalent bumblebee parasite Crithidia bombi. Journal of Invertebrate Pathology 148, 81-85

Free, J.B. and Butler, R.F. (1959) Bumblebees. Collins Press; London, UK.

Fussell, M. and Corbet, S.A. (1992) The nesting places of some British bumblebees. Journal of Apicultural Research 31, 32-41.

Goulson, D. (2010) Bumblebees; their behaviour, ecology and conservation. Oxford University Press; Oxford, UK. 
596

Goulson, D. and Stout, J.C. (2001) Homing ability of the bumblebee Bombus terrestris (Hymenoptera: Apidae). Apidologie 32, 105-111.

Goulson, D., Hughes, W.O.H., Derwent, L.C. and Stout, J.C. (2002) Colony growth of the bumblebee, Bombus terrestris in improved and conventional agricultural and suburban habitats. Oecologia 130, 267-273.

Goulson D, Lepais O, O’Connor S, Osborne JL, Sanderson RA, Cussans J, Goffe L \& Darvill B. (2010) Effects of land use at a landscape scale on bumblebee nest density and survival. Journal of Applied Ecology 46: 1207-1215

Goulson, D., Nicholls E., Botías C., \& Rotheray, E.L. (2015) Combined stress from parasites, pesticides and lack of flowers drives bee declines. Science 347: 1435-+.

Graystock, P., Goulson, D., \& Hughes, W.O.H. 2015. Parasites in bloom: flowers aid dispersal and transmission of pollinator parasites within and between bee species. Proceedings of the Royal Society B 282: 20151371

Imhoof, B. and Schmid-Hempel, P. (1999) Colony success of the bumblebee, Bombus terrestris, in relation to infections by two protozoan parasites, Crithidia bombi and Nosema bombi. Insectes Sociaux 46, 233-238.

Kells, A.R. and Goulson, D. (2003) Preferred nesting sites of bumblebee queens (Hymenoptera: Apidae) in agroecosystems in the UK. Biological Conservation 109, 165-174.

Lopez-Vaamonde, C., Koning, J.W., Brown, R.M., Jordan, W.C. and Bourke, A.F.G. (2004) Social parasitism by male-producing reproductive workers in a eusocial insect. Nature 430, 557-560.

Lye GC, Park K, Osborne JL, Holland J and Goulson D. (2009). Assessing the value of Rural Stewardship schemes for providing foraging resources and nesting habitat for bumblebee queens (Hymenoptera: Apidae). Biological Conservation 142: 2023-2032

Lye, G.C., Osborne, J.L., Park, K.J. and Goulson, D. (2012) Using citizen science to monitor Bombus populations in the UK: nesting ecology and relative abundance in the urban environment. Journal of Insect Conservation 16, 697-707.

Müller, C.B. and Schmid-Hempel, P. (1992) Correlates of reproductive success among field colonies of Bombus lucorum: the importance of growth and parasites. Ecological Entomology 17, 343-353. 
Müeller, U.G. and Wolfmueller, B. (1993) A method for estimating the age of bees - Age dependent wing wear and coloration in the Wool-Carder Bee Anthidium manicatum (Hymenoptera, Megachilidae). Journal of Insect Behavior 6, 529-537.

O’Connor, S. (2013) The nesting ecology of bumblebees. PhD thesis, University of Stirling.

O’Connor, S., Park, K.J. and Goulson, D. (2012) Humans versus dogs; a comparison of methods for the detection of bumblebee nests. Apidologie 51, 204-211.

O'Connor, S., Park, K.J. and Goulson, D. (2013) Worker drift and egg-dumping by queens in wild Bombus terrestris colonies. Behavioral Ecology and Sociobiology 67, 621-627.

Osborne, J.L., Martin, A.P., Shortall, C.R., Todd, A.D., Goulson, D., Knight, M.E., Hale, R.J. and Sanderson, R.A. (2008) Quantifying and comparing bumblebee nest densities in gardens and countryside habitats. Journal of Applied Ecology 45, 784-792.

Otterstatter, M.C. and Thomson, J.D. (2006) Within-host dynamics of an intestinal pathogen of bumblebees. Parasitology 133, 749-761.

Otti, O. and Schmid-Hempel, P. (2007) Nosema bombi: A pollinator parasite with detrimental fitness effects. Journal of Invertebrate Pathology 96, 118-124.

Otti, O. and Schmid-Hempel, P. (2008) A field experiment on the effect of Nosema bombi in colonies of the bumblebee Bombus terrestris. Ecological Entomology 33, 577-582.

Paxton, R.J., Thoren, P.A., Estoup, A. and Tengo, J. (2001) Queen-worker conflict over male production and the sex ratio in a facultatively polyandrous bumblebee, Bombus hypnorum: the consequences of nest usurpation. Molecular Ecology 10, 2489-2498.

Popp, M., Erler, S. and Lattorff, H.M.G. (2012) Seasonal variability of prevalence and occurrence of multiple infections shape the population structure of Crithidia bombi, an intestinal parasite of bumblebees (Bombus spp.). Microbiology Open 1, 362-372.

Pouvreau, A. (1973) The Enemies of Bumblebees. Apidologie 4, 103-148.

Rodd, F.H., Plowright R.C. and Owen R.E. (1980) Mortality rates of adult bumble bee workers (Hymenoptera: Apidae). Canadian Journal of Zoology 58, 1718-1721.

Rutrecht, S.T., Klee, J. and Brown, M.J.F. (2007) Horizontal transmission success of Nosema bombi to its adult bumblebee hosts: effects of dosage, spore source and host age. Parasitology 134, 1719-1726.

Schmid-Hempel, R. and Schmid-Hempel, P. (1998) Colony performance and immunocompetence of a social insect, Bombus terrestris in poor and variable environments. Functional Ecology 12, 22-30.

Shykoff, J.A. and Schmid-Hempel, P. (1991) Parasites delay worker reproduction in bumblebees: consequences for eusociality. Behavioural Ecology 2, 242-248. 
662 Sladen, F.W.L. (1912) The Humble-bee. Macmillan and Co. Ltd., Hereford, UK.

663 Suzuki, Y., Kawaguchi, L.G., Munidasa, D.T. and Toquenaga, Y. (2009) Do bumblebee

664

665

666

667

668

669

670

671

672

673

674

675

676

677

678

679

680

681

682

683

684

685

686 queens choose nest sites to maximize foraging rate? Testing models of nest site selection. Behavioural Ecology and Sociobiology 63, 1353-1362.

Svensson, B., Lagerlof, J. and Svensson, B.G. (2000) Habitat preferences of nest-seeking bumblebees (Hymenoptera: Apidae) in an agricultural landscape. Agriculture, Ecosystems and Environment 77, 247-255.

Waters, J., O’Connor, S., Park, K.J. and Goulson, D. (2011). Testing a Detection Dog to Locate Bumblebee Colonies and Estimate Nest Density. Apidologie 42: 200-205

Whitehorn, P.R., Tinsley, M.C., Brown, M.J.F., Darvill, B., Goulson, D. (2011) Genetic diversity, parasite prevalence and immunity in wild bumblebees. Proceedings of the Royal Society B: Biological Sciences 278, 1195-1202.

Whitehorn, P.R., O’Connor, S., Wackers, F.L. and Goulson, D. (2012) Neonicotinoid pesticide reduces bumblebee colony growth and queen production. Science 336, 351-352.

Winfree, R., (2010) The conservation and restoration of wild bees. Annals of the New York Academy of Sciences 1195, 169-197.

Zuur, A., Ieno, E.N. and Smith, G.M. (2007) Analysing Ecological Data. Springer, USA. pp64.

Figure 5. Total number of great tit attacks in relation to peak traffic of nests. Points 8 and 23 were removed from the analysis as they had Cook's distance greater than 1 (i.e. they were overly influential outliers; Zuur et al., 2007). 
688 Figure 1 (a) Total nests and presence or absence of new gynes, for all species. (b) Mean bee peak of 689 traffic for nests with and without new gynes (filmed nests only). (c) Mean of total days nests were 690 observed for. Error bars in $b$ and c show standard errors of means.

691

692 Figure 2a. Great tit depredating B. terrestris (nest 1; Table 1); (b) Hedgehog 'rooting' in leaves at nest entrance (nest 1; Table 1).

694

695

Figure 3. Wood mouse visits during $24 \mathrm{hr}$ and daily bumblebee midday hourly traffic at (a) nest 23 ( $B$. hortorum) and (b) nest 16 (B. terrestris). Breaks in lines indicate loss of footage. Wood mice transported leaf litter into nest entrances during visits.

698

699 Figure 4 (a) Wood mice transported leaf litter into B. terrestris nest entrance (nest 16; Table 1). (b)

700 Nest tunnel and external entrance was blocked by leaves and sticks placed by wood mice several 701 hours later. Bumblebee traffic ceased.

702

Figure 5. Total number of great tit attacks in relation to peak traffic of nests. Points 8 and 23 were removed from the analysis as they had Cook's distance greater than 1 (i.e. they were overly influential outliers; Zuur et al., 2007).

Figure 6. (a) More shrews were recorded visiting nests in 2011 than in 2010 (mean and standard errors); (b) There was no relationship between shrew visits and peak bumblebee traffic. * Points 23 and 15 were removed from statistical analysis as they were overly influential on the data set (Cook's distance of >1; Zuur et al., 2007).

Figure 7. Mean great tit attacks (a) and wax moth events (b) to nests with and without gyne production (error bars show standard errors).

Figure 8 (a) B. lapidarius nest (b) visited by B. terrestris or B. lucorum worker. The footage allows identification from the different stripe patterns between some species. (The red tail of B. lapidarius appears white.)

Figure 9. Proportion of B. terrestris infected with C. bombi and $N$. bombi within each age class $(0=$ no wing wear; $1=$ some indentations; $2=<5 \%$ of wing surface damaged; $3=>5 \%$ wing wear absent). 
723 Figure 10. Proportion of worker B. terrestris infected with C. bombi, throughout the experiment in (a) $724 \quad 2010$ and (b) 2011.

725

726 Figure 11. Intensity of C. bombi infections in B. terrestris from two typical nests for the duration of 727 observations (Ref 16 and 26; Table 1; (a) and (b) respectively).

728

729 Figure 12. Mean proportion of B. terrestris workers infected with C. bombi from 29 nests, with and 730 without gyne production (with interquartile ranges, maximum and minimum values shown). 
732 Table 1. Longevity, gyne production and the proportion of bees hosting C. bombi and N. bombi

733 infections for filmed nests. *Nest which failed prior to filming; >2 bees were seen to enter or leave,

734 but footage revealed few/no further bee traffic. These were excluded from predation analysis.

Nest details

\begin{tabular}{|c|c|c|c|c|c|c|c|c|}
\hline No. & Species & Habitat & Start & End & $\begin{array}{c}\text { Gynes } \\
\text { Produced }\end{array}$ & C. bombi & N. bombi & (n) \\
\hline 1 & B. terrestris & Woodland & $19 / 07 / 10$ & $17 / 08 / 10$ & Yes & 0.46 & 0.05 & 39 \\
\hline 2 & B. terrestris & Woodland & $27 / 07 / 10$ & $17 / 08 / 10$ & Yes & 0.74 & 0.03 & 35 \\
\hline 3 & B. terrestris & Woodland & $15 / 06 / 10$ & $26 / 07 / 10$ & No & 0.92 & 0.08 & 26 \\
\hline 4 & B. terrestris & Woodland & 09/08/10 & $18 / 08 / 10$ & No & 1.00 & 0.50 & 2 \\
\hline 5 & B. terrestris & Grassland & $29 / 07 / 10$ & $16 / 09 / 10$ & Yes & 0.48 & 0.05 & 65 \\
\hline 6 & B. hortorum & Grassland & $25 / 06 / 10$ & $05 / 08 / 10$ & Yes & 0.43 & 0.11 & 37 \\
\hline 7 & B. hortorum & Grassland & $19 / 06 / 10$ & $25 / 07 / 10$ & No & 0.62 & 0.12 & 34 \\
\hline 8 & B. lapidarius & Woodland & $27 / 07 / 10$ & $10 / 08 / 10$ & Yes & 0.50 & 0.00 & 6 \\
\hline 9 & B. pratorum & Grassland & $10 / 06 / 10$ & 08/07/10 & No & 0.80 & 0.07 & 15 \\
\hline 10 & B. terrestris & Grassland & $13 / 06 / 10$ & $28 / 07 / 10$ & No & 0.34 & 0.00 & 29 \\
\hline 11 & B. terrestris & Woodland & $22 / 06 / 10$ & $30 / 07 / 10$ & Yes & 0.50 & 0.06 & 34 \\
\hline 12 & B. terrestris & Woodland & 09/08/10 & $20 / 08 / 10$ & No & 0.29 & 0.00 & 7 \\
\hline 13 & B. terrestris & Woodland & $18 / 08 / 10$ & $22 / 08 / 10$ & Yes & 0.60 & 0.20 & 5 \\
\hline 14 & B. lucorum & Woodland & $16 / 06 / 10$ & $29 / 08 / 10$ & Yes & 0.51 & 0.03 & 63 \\
\hline 15 & B. terrestris & Woodland & $22 / 06 / 10$ & $27 / 07 / 10$ & Yes & 0.65 & 0.18 & 55 \\
\hline 16 & B. terrestris & Woodland & $13 / 08 / 10$ & 06/09/10 & Yes & 0.28 & 0.01 & 80 \\
\hline 17 & B. terrestris & Woodland & $16 / 06 / 10$ & $16 / 07 / 10$ & No & 1.00 & 0.00 & 9 \\
\hline 18 & B. terrestris & Woodland & $29 / 06 / 10$ & $16 / 08 / 10$ & Yes & 0.39 & 0.07 & 61 \\
\hline 19 & B. terrestris & Woodland & $19 / 06 / 10$ & 03/09/10 & Yes & 0.69 & 0.21 & 94 \\
\hline 20 & B. pratorum & Woodland & $31 / 05 / 11$ & $20 / 06 / 11$ & No & - & - & - \\
\hline 21 & B. terrestris & Woodland & $01 / 06 / 11$ & 08/08/11 & No & 0.55 & 0.02 & 60 \\
\hline 22 & B. terrestris & Woodland & $01 / 06 / 11$ & $29 / 08 / 11$ & No & 0.27 & 0.01 & 138 \\
\hline 23 & B. hortorum & Woodland & 01/06/11 & 08/08/11 & No & 0.38 & 0.00 & 13 \\
\hline 24 & B. terrestris & Woodland & $02 / 06 / 11$ & $11 / 07 / 11$ & No & 0.71 & 0.00 & 24 \\
\hline 25 & B. terrestris & Grassland & 02/06/11 & $29 / 06 / 11$ & No & 0.50 & 0.00 & 10 \\
\hline 26 & B. terrestris & Grassland & 06/06/11 & 02/09/11 & Yes & 0.38 & 0.02 & 112 \\
\hline $27 *$ & B. terrestris & Woodland & 09/06/11 & $15 / 06 / 11$ & No & - & - & - \\
\hline 28 & B. terrestris & Woodland & $14 / 06 / 11$ & $23 / 06 / 11$ & No & 1.00 & 0.00 & 1 \\
\hline $29 *$ & B. terrestris & Woodland & $23 / 06 / 11$ & $24 / 06 / 11$ & No & - & - & - \\
\hline 30 & B. terrestris & Woodland & $27 / 06 / 11$ & 01/09/11 & Yes & 0.27 & 0.00 & 75 \\
\hline 31 & B. terrestris & Woodland & $12 / 07 / 11$ & $28 / 09 / 11$ & No & 0.38 & 0.00 & 58 \\
\hline 32 & B. terrestris & Woodland & $22 / 07 / 11$ & 10/09/11 & Yes & 0.33 & 0.00 & 51 \\
\hline
\end{tabular}

Proportion of infected bees

Period of filming 
736 Table 2. Interactions with animals observed on the cameras. Invertebrate observations were not

737 recorded, with the exception of wax moths and their larvae.

\begin{tabular}{|c|c|c|c|}
\hline Species (common name) & Events & Nests & $\begin{array}{l}\text { Summary of interactions with nests ( } n=\text { number of } \\
\text { times observed) }\end{array}$ \\
\hline \multicolumn{4}{|l|}{ Large mammals } \\
\hline Vulpes vulpes (fox) & 4 & 4 & No interaction \\
\hline Mustela erminea (stoat) & 12 & 5 & Enter and leave (1) \\
\hline Erinaceus europaeus (hedgehog) & 34 & 15 & Attempts to gain access (7) \\
\hline Sciurus carolinensis (grey squirrel) & 157 & 22 & $\begin{array}{l}\text { Sniffed at or near entrance (32), looked in hole or dug at } \\
\text { nearby leaves ( } 7)\end{array}$ \\
\hline Oryctolagus cuniculus (rabbit) & 207 & 22 & Sniffed at entrance (34), entered hole (1) \\
\hline Lepus europaeus (hare) & 7 & 3 & No interaction \\
\hline Capreolus capreolus (roe deer) & 8 & 4 & No interaction \\
\hline Ovis aries (sheep) & 1 & 1 & No interaction \\
\hline Felis catus (cat) & 6 & 3 & No interaction \\
\hline Canis lupus familiaris (dog) & 1 & 1 & No interaction \\
\hline Bos primigenius (cow) & 9 & 1 & No interaction \\
\hline \multicolumn{4}{|l|}{ Small mammals } \\
\hline $\begin{array}{l}\text { Clethrionomys glareolus (bank } \\
\text { vole) }\end{array}$ & 17 & 4 & Enter and leave (8) \\
\hline Microtus arvalis (field vole) & 70 & 3 & Enter and leave (21) \\
\hline Apodemus sylvaticus (wood mouse) & 1396 & 18 & Enter and leave (837) \\
\hline Unidentified small mammal & 16 & 7 & Enter and leave (16) \\
\hline Sorex spp. (shrew species) & 162 & 10 & Enter and leave (56) \\
\hline \multicolumn{4}{|l|}{ Reptiles and Amphibians } \\
\hline Lacerta vivipara (common lizard) & 1 & 1 & No interaction \\
\hline Rana tempora (frog) & 7 & 5 & No interaction \\
\hline Bufo bufo (toad) & 5 & 3 & No interaction \\
\hline \multicolumn{4}{|l|}{ Birds } \\
\hline Anas platyrhynchos (mallard) & 1 & 1 & No interaction \\
\hline Columba palumbus (wood pigeon) & 8 & 3 & No interaction \\
\hline $\begin{array}{l}\text { Corvus corone corone (carrion } \\
\text { crow) }\end{array}$ & 16 & 4 & Pecking at hole and widening entrance (5) \\
\hline Erithacus rubecula (robin) & 29 & 12 & $\begin{array}{l}\text { Investigation/waiting at nest (5) possible attempted } \\
\text { predation of worker (1) }\end{array}$ \\
\hline Fringilla coelebs (chaffinch) & 20 & 6 & Looking at or waiting at hole (3) no bee chases or kills \\
\hline $\begin{array}{l}\text { Haematopus ostralegus (oyster } \\
\text { catcher) }\end{array}$ & 12 & 1 & No interaction; Investigating entrance (1) \\
\hline Turdus merula (blackbird) & 28 & 13 & $\begin{array}{l}\text { Investigating/waiting at hole (5) Possible attempted } \\
\text { predation of worker (1) }\end{array}$ \\
\hline Turdus spp. (thrush other) & 10 & 6 & Entrance investigated (1), no traffic and no predation \\
\hline Parus caeruleus (blue tit) & 1 & 1 & No interaction \\
\hline Parus major (great tit) & 60 & 10 & Predations (10) attempted predations (22) 'stalking' (17) \\
\hline $\begin{array}{l}\text { Passer montanus } \\
\text { (tree sparrow) }\end{array}$ & 6 & 4 & No interaction \\
\hline Pica pica (magpie) & 1 & 1 & No interaction \\
\hline Prunella modularis (dunnock) & 22 & 4 & Investigating/waiting at entrance (6) no bee chases or kills \\
\hline Troglodytes troglodytes (wren) & 11 & 7 & No interaction \\
\hline \multicolumn{4}{|l|}{ Wax moth } \\
\hline Aphomia sociella & 19 & 8 & Enter and leave (19) \\
\hline
\end{tabular}



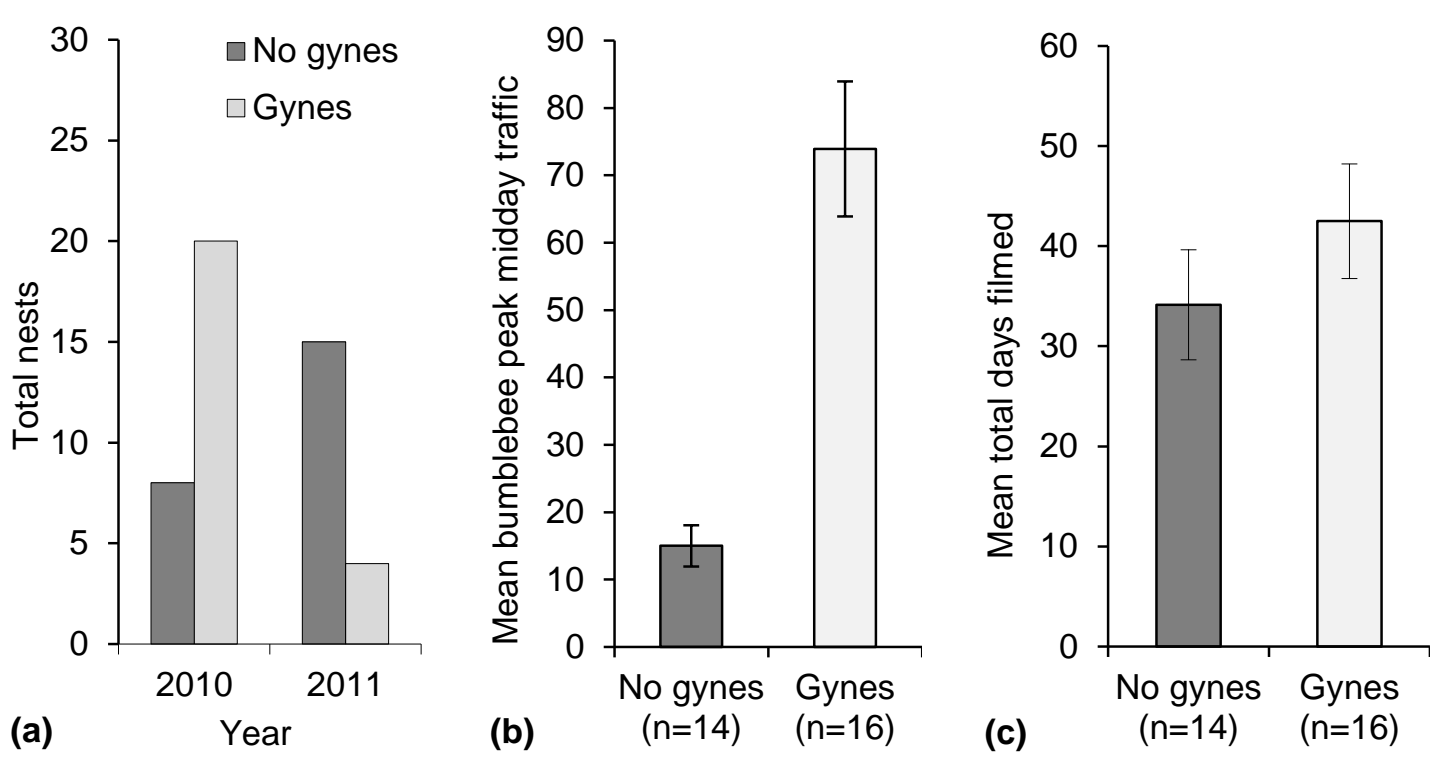

741

$742 \quad$ Figure 1

743

744

745

746

747

748
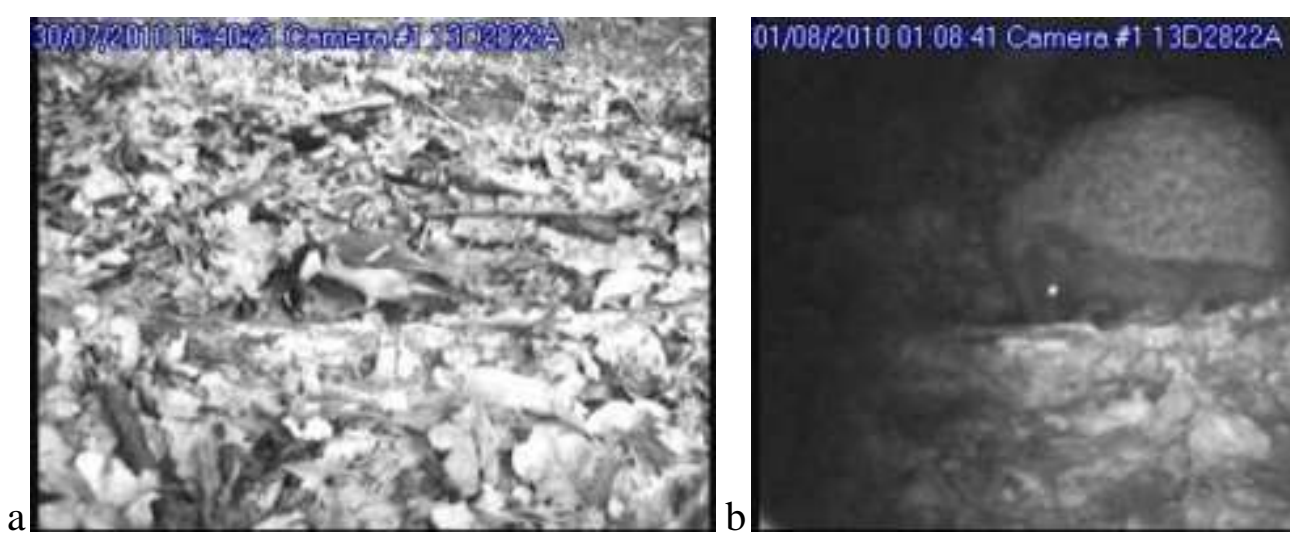

749

Figure 2 
751

(a)

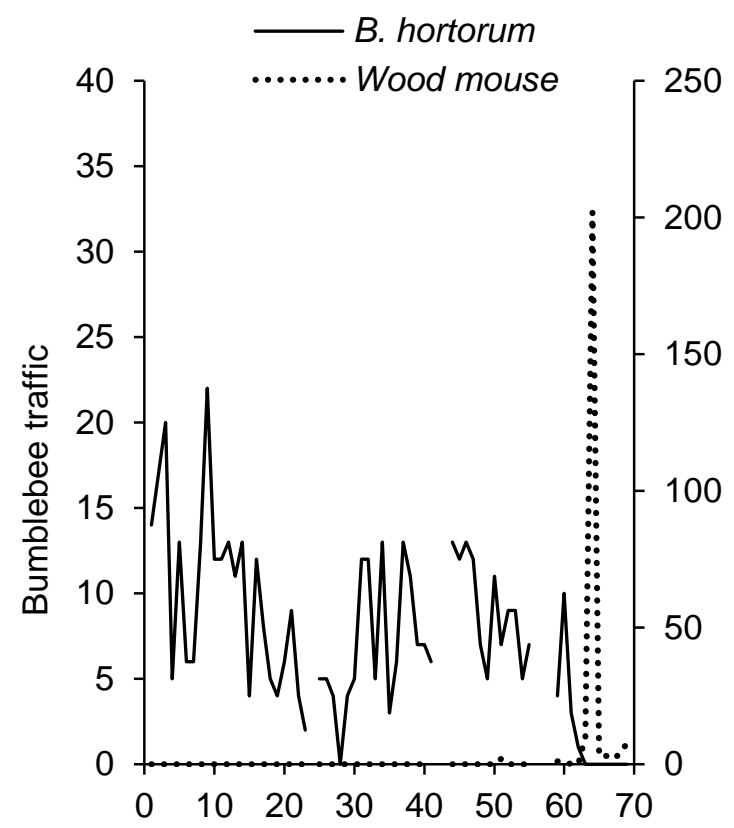

752

753 Figure 3

754

755

756

757

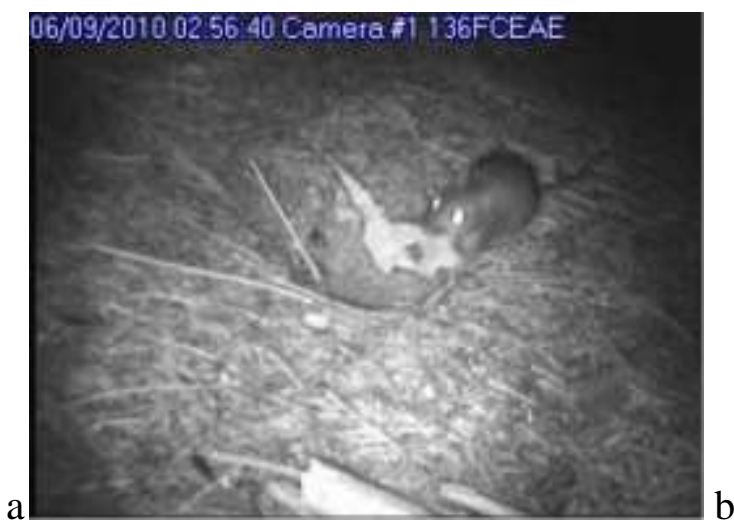

$758 \quad$ Figure 4 (b)

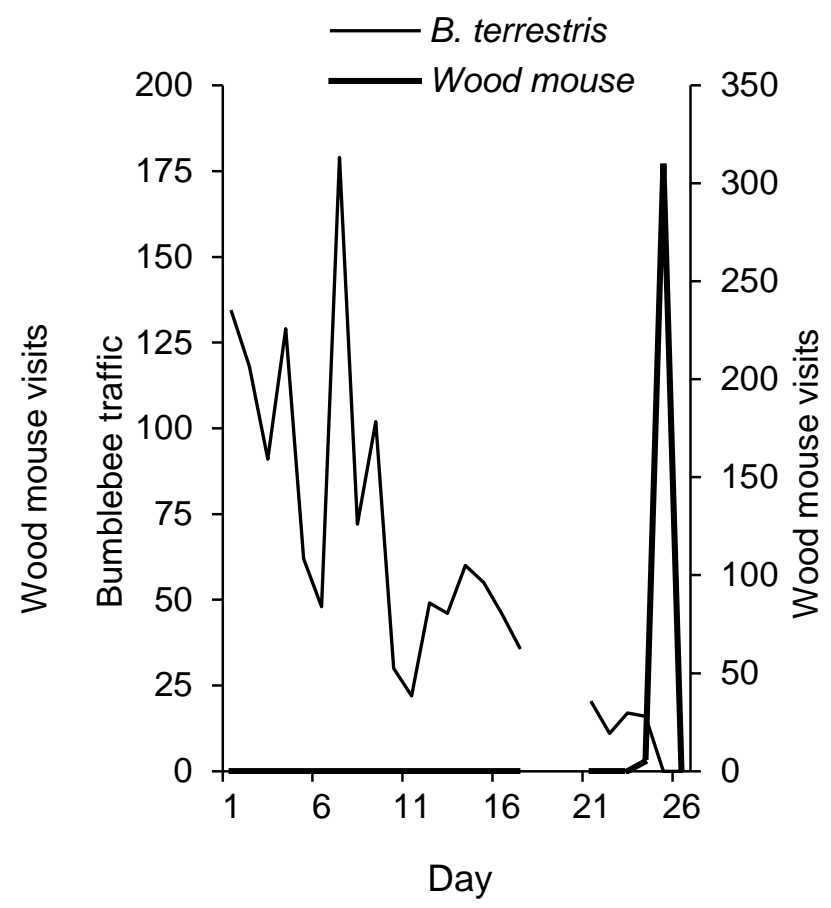

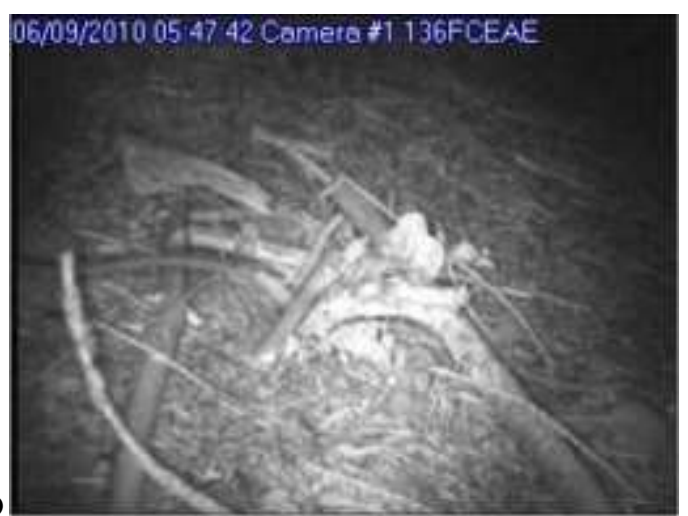




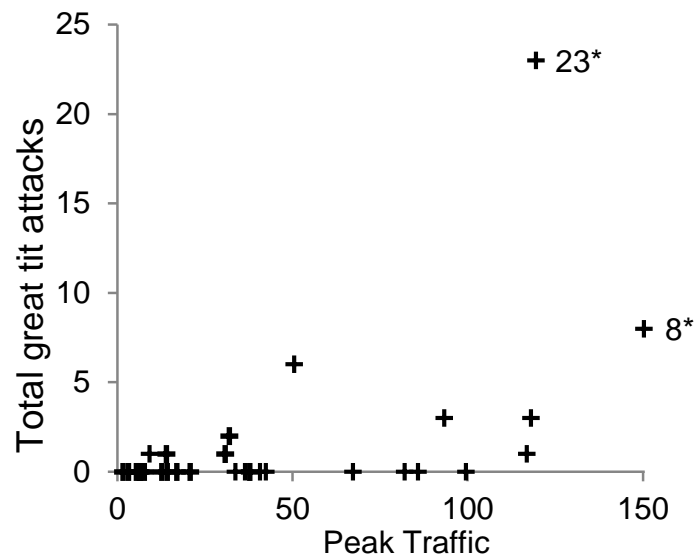

761 Figure 5.

762

763

764

765

(a)

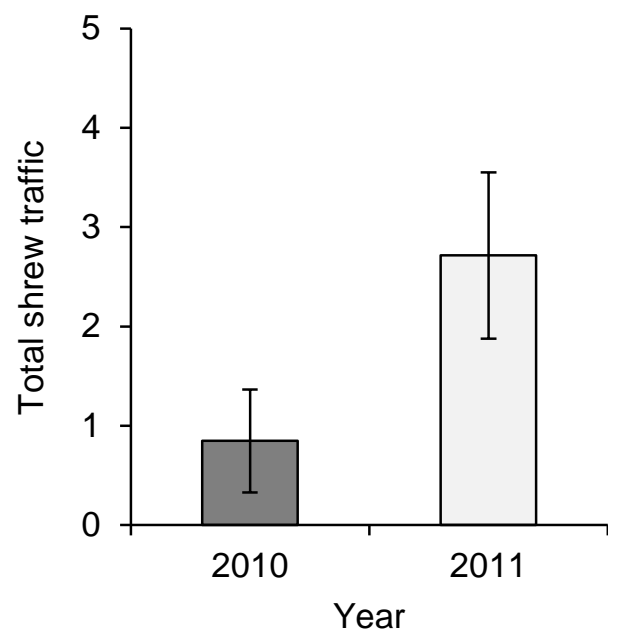

766

767 Figure 6. (b)

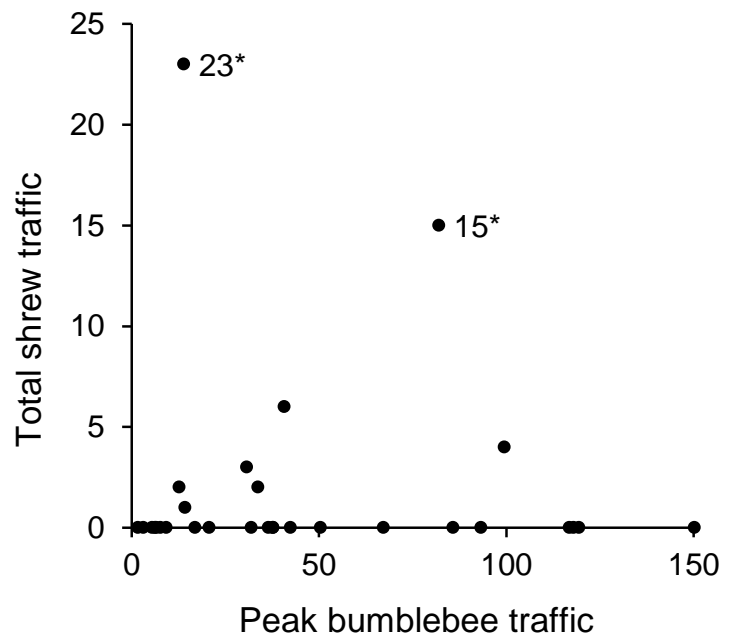



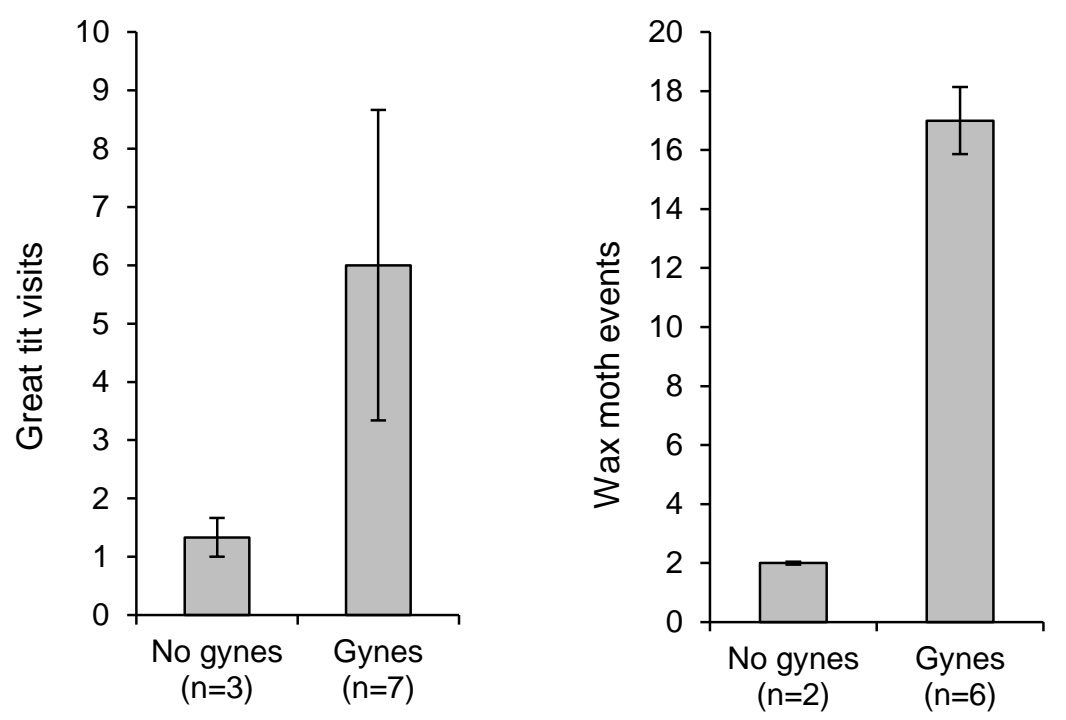

770

(a) Reproductive status of nest

(b)

Reproductive status of nest

$771 \quad$ Figure 7.

772

773

774 (a)

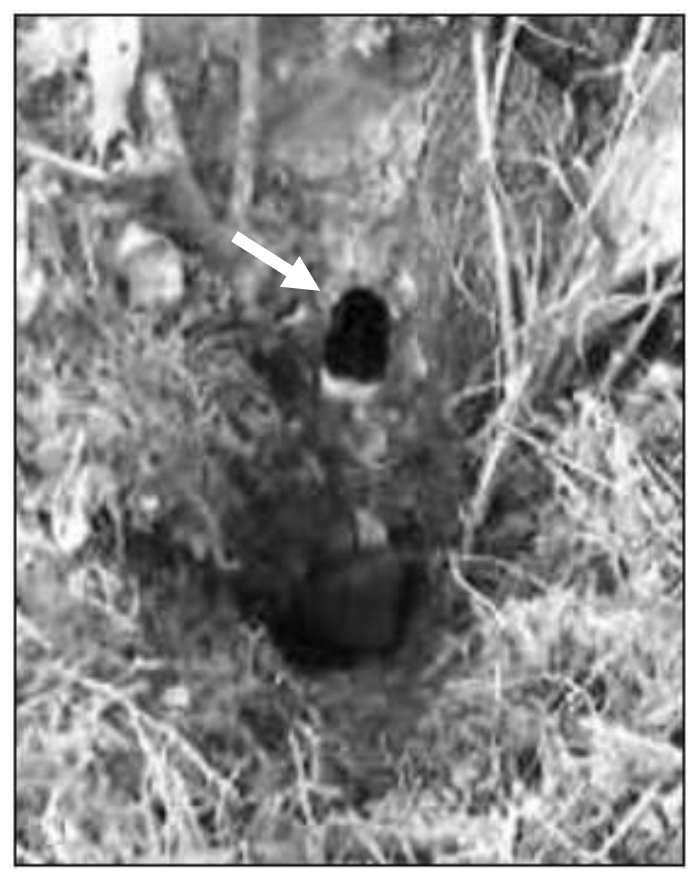

(b)

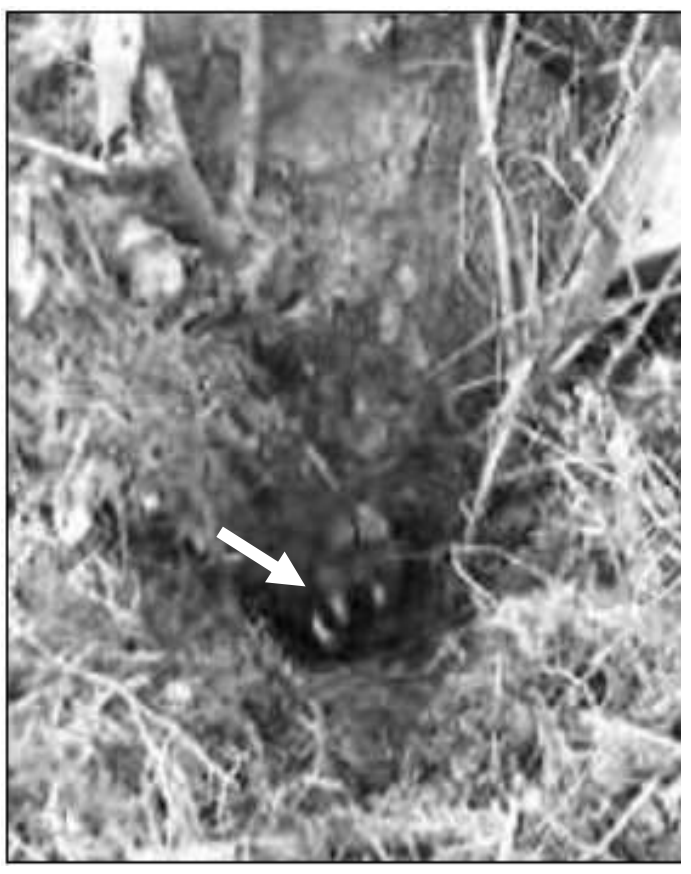

$775 \quad$ Figure 8 


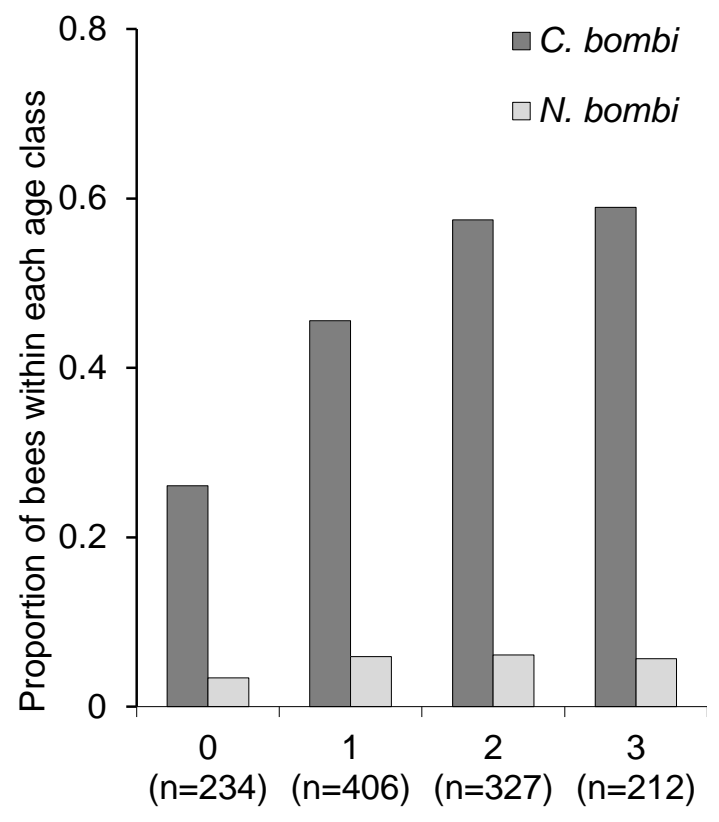

777

Age class of bumblebee

778 Figure 9.

779

780

781
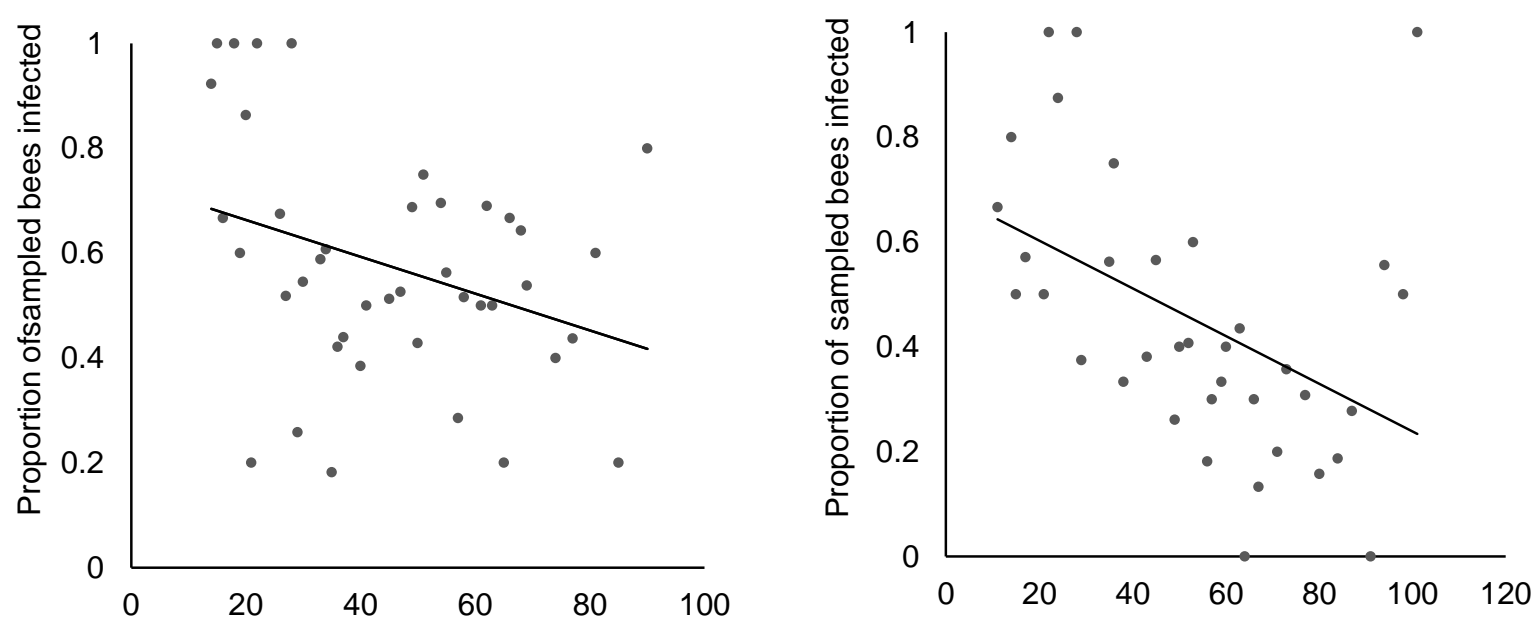

782

(a)

Day number

(b)

Day number

783

784 Figure 10.

785 
(a)

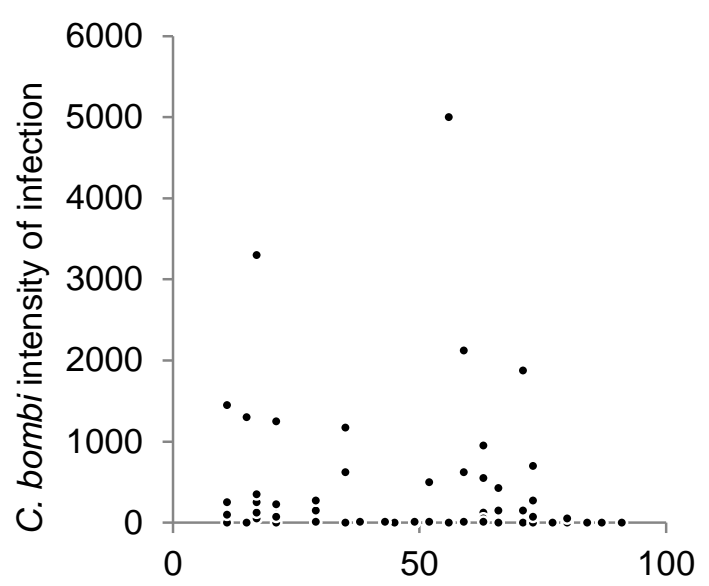

787

788

789

790

791

792

793

794$$
\text { 要 }
$$

795

Day number

Figure 11 (b)

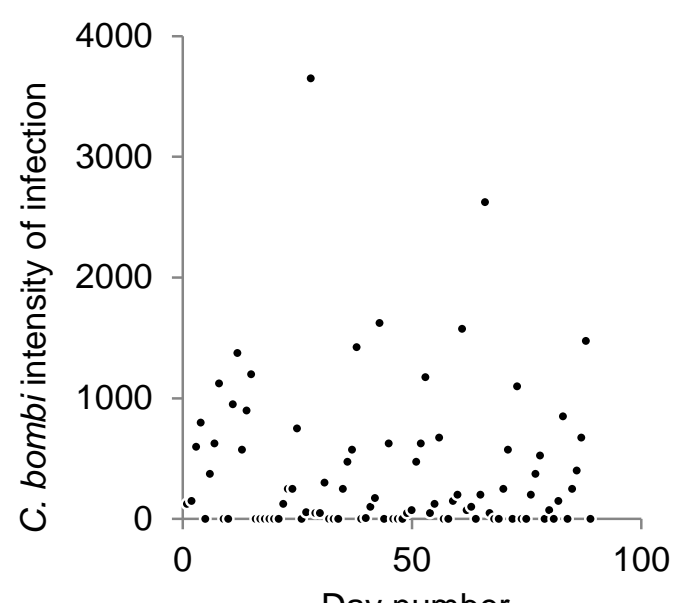

Day number

796 Figure 12

797 